\section{Marine Geology}

Vol. 234, Issues 1-4 , 18 Dec. 2006, Pages 261-270

http://dx.doi.org/ 10.1016/j.margeo.2006.09.016

(c) 2006 Elsevier B.V. All rights reserved
Archimer, archive institutionnelle de l'fremer http://www.ifremer.fr/docelec/

\title{
Sedimentary structures offshore Ortona, Adriatic Sea - Deformation or sediment waves?
}

\author{
Christian Berndt ${ }^{\mathrm{a},{ }^{\star}}$, Antonio Cattaneo $^{\mathrm{b}}$, Magdalena Szuman ${ }^{\mathrm{a}, 1}$, Fabio Trincardi $^{\mathrm{c}}$ and Doug Masson ${ }^{\mathrm{a}}$
}

\author{
${ }^{a}$ National Oceanography Centre, European Way, Southampton, SO14 3ZH, UK \\ ${ }^{\mathrm{b}}$ Ifremer, Centre de Brest, Plouzané, France \\ 'ISMAR-CNR, Bologna, Italy \\ *: Corresponding author : $\underline{\text { cbe@noc.soton.ac.uk }}$
}

\begin{abstract}
:
The late Holocene mud wedge on the Adriatic shelf offshore Ortona, Italy, shows undulating subparallel seismic reflector sequences which extend several kilometres along strike and 100-200 m down-dip in water depth between 20 and $80 \mathrm{~m}$. The amplitude of such undulations is up to $5 \mathrm{~m}$ and the undulations continue as stacked sediment packages downwards throughout the $35 \mathrm{~m}$ thick mud wedge. The undulations are separated by $4^{\circ}$ to $5^{\circ}$ dipping boundary zones and at first glance these sediment undulations resemble the seafloor sedimentary structures visible in the Humboldt Feature offshore California. There is an ongoing debate whether seafloor undulations are the result of deformation processes or sediment deposition and/or reworking due to submarine shelf currents. A dense net of recently reprocessed and digitally interpreted high-resolution Chirp seismic data on the Adriatic shelf favours an interpretation that these undulations developed, in the upper part of the stratigraphic section through sediment reworking rather than through deformation. There are three lines of evidence for this: (1) the spatial extent of the undulations coincides with higher seabed reflector amplitudes than found both on the shelf and in the distal part of the shelf. If the features were solely caused by slope failure there should be no change of amplitudes, (2) the seabed reflector amplitude is generally higher on the gently dipping or flat upslope limbs than on the steeper downslope limbs, supporting a current origin that causes preferred deposition of sediments with higher acoustic impedance on the top, (3) the boundaries between the undulations are dipping at angles that are much lower than the angle of internal friction of these sediments excluding that a simple model like the Mohr-Coulomb under gravitational loading could describe the undulations as sediment deformation and failures.
\end{abstract}

Keywords: sediment waves; submarine creep; seismic amplitudes; Adriatic Sea 


\section{Introduction}

The seafloor is frequently affected and shaped by instabilities as a result of gravitational forces and other forces including earthquakes and waves. The resulting mass movements are controlled by diverse processes and take the form of rotational slumping, debris flows or turbidity currents (Mulder and Cochonat, 1996). In phenomenon in subaerial soils. However, the subaerial creep process depends on differential saturation of soil, and it can therefore not occur in a shallow marine environment. Moreover, lateral displacement in subaerial creep decreases downward resulting in a geometry that is very different from the submarine type localities. These include the margins off Oregon and Alaska, the Gulf of Mexico and the Adriatic Sea (Carlson, 1978; Hill et al., 1982; Lee and Baraza, 1999; Locat and Lee, 2000; Correggiari et al., 2001). However, because the suggested submarine creep structures are so different from their subaerial counterparts, the concept of creep was challenged and other authors invoked purely depositional processes to explain the observed slope geometries. These processes include bottom-current driven sediment wave development either as a result of Ekman transport, internal tide or down-slope density currents, similar to deep-sea turbidity current sediment waves. Numerical modelling studies demonstrate that bottom turbidity currents could produce the observed geometries (Lee et al., 2002).

On the western Adriatic continental shelf (Fig. 1), an up to $35 \mathrm{~m}$ thick mud wedge was deposited during the last ca. $6 \mathrm{kyr}$, after sea level attained the present position (Cattaneo et al., 2003a). The overall clinoform geometry of this wedge is "perturbed" over as much as $40 \%$ of its extent by surface and subsurface undulations (Hovland and Curzi, 1989; Correggiari et al., 2001). The upper shelf, i.e. water depth between 20 and $80 \mathrm{~m}$ is deformed by undulations that strike shelf parallel, i.e. NNW-SSE. Undulations are 50 to $250 \mathrm{~m}$ wide and have a surface relief of up to $5 \mathrm{~m}$. The undulations comprise at least the uppermost third of the mud wedge, and possibly also the lower part down to the maximum flooding surface. However, the seismic data suggest that the undulations are less pronounced in the lower part of the mud wedge (Figs. 2 and 5). Below approximately $80 \mathrm{~m}$ water depth the seabed is characterized by distinctly different mud relief features (Marsset et al., 2004; Trincardi et al., 2004). Here the prominent strike is SW-NE and the seabed irregularities are underlain by isolated, seismically transparent mound-like structures that penetrate the Holocene highstand systems tract and reach down to the maximum flooding surface. Geochronologic data indicate that the unit at the base of the HST, above the maximum flood surface (mfs), marks a condensed interval between approximately 5.5 and $3.7 \mathrm{kyr}$ (Correggiari et al., 2001). Above this condensed unit, which is characterized by discontinuous seismic reflectors at the top, the sediment accumulation rate is higher and the succession is characterised by seafloor and subsurface undulations interpreted as sediment deformation features with limited displacement, muddy bedforms, or a combination (Correggiari et al., 2001; Lee et al., 2002; Cattaneo et al., 2004).

The origin of the undulations on the upper shelf has been subject of debate. Initially, the boundaries between the undulations were interpreted as fault planes (Correggiari et al., 2001). It was also proposed that these structures are deforming plastically and that they result from a combination of mechanical and depositional processes including sediment deformation followed by preferential sediment deposition over a seafloor "irregularity" (Cattaneo et al., 2004). The same kind of ambiguity applies to several other cases on continental margins. For example on the Eel River shelf in northern California seafloor undulations were initially interpreted as a submarine slide (Humboldt Slide, Gardner et al., 1999), but later sedimentological work by Lee et al. (2002) suggested that a sediment wave origin is more likely.

The objective of this work is to better understand the relevance of deformational and depositional processes for the development of seafloor undulation offshore Ortona, Italy. The geophysical analysis presented here complements previously published sedimentological work (Cattaneo et al., 2004). 


\section{Methods}

\subsection{Chirp data}

Chirp data are high-resolution seismic data that are collected using piezo-electric transducers and receivers similar to conventional $3.5 \mathrm{kHz}$ sediment profilers. The main difference is that the emitted pulse is known and can be used to obtain a much clearer seismic image through pulse deconvolution (Clay and Liang, 1962; Schock et al., 1989; Bull et al., 1998; Quinn et al., 1998). The Chirp data were collected onboard R/V Urania with the in-built Benthos Chirp system using a 2 to $10 \mathrm{kHz}$ sweep. Before recording, the data were convolved with the source sweep and the amplitudes were automatically squared. This enhances the reflectivity contrast at the cost of phase information. This process suffices for sub-bottom sediment profiling, but renders the data unsuitable for standard interactive seismic interpretation tools. As the seismic acquisition system onboard R/V Urania cannot record the raw data it was decided to filter the data with a zerophase Ormsby filter with a bandwidth of 500-700-5500-6000 Hz. This results in positive and negative values for the seismic traces, which could subsequently be interpreted and relative amplitude variations could be extracted using KingdomSuite automatic picking routines (Figs. 2 and 3). It has to be noted, however, that the individual phases in the seismic data lose their physical meaning as a result of this procedure, but this is an inherent problem with this kind of Chirp data, i.e. even two local maxima in the unprocessed sub-bottom profiler records can be caused by two or three impedance changes in the sub-surface depending on their interference. The fact that the amplitudes are squared means that this cannot be distinguished using the waveform. Therefore, low-pass filtering does not decrease the information content in the data. The entire re-processed data set was loaded into KingdomSuite to extract the relative amplitude variations for key horizons.

2.2. Widescan sonar data Widescan is a high-resolution side-scan sonar that operates at $100 \mathrm{kHz}$ (Le Bas and Masson, 1995; Masson et al., 2000). Although this should result in sub-meter resolution, crossover analysis between adjacent sail lines suggests that absolute accuracy is approximately 20 $\mathrm{m}$, because of navigation errors. The final backscatter mosaic was processed at $0.2 \mathrm{~m}$ resolution. At this resolution numerous trawl marks and other small-scale structures can be discerned. However, because of the navigation uncertainties the data were down-sampled to $15-\mathrm{m}$ resolution. All data processing was carried out with PRISM software - the National Oceanography Centre's in-house software package. The final map compilation was completed in ERDASImagine. The processes applied to the raw data include merging of the ship navigation with cable length data, radiometric correction for vehicle roll, removing near nadir shading effects, across-track equalisation of illumination, high pass and low pass filtering and smoothing of the Widescan position values.

\section{Observations}

\subsection{Geometries}

At 15-m resolution the newly processed Widescan sonar data (Fig. 4b) show the geometry of the seabed undulations. Two distinct groups of amplitude variations strike parallel to the bathymetric slope. There are pronounced amplitude lows with a distance of 400 to $600 \mathrm{~m}$ that do not correlate with the seabed topography and that cannot be picked up in the seabed amplitudes of the Chirp data (Fig. 4a). The high backscatter areas generally strike along the topography, but they are discontinuous patches (red lines in Fig. 4b). In addition there are less pronounced amplitude variations with distances between 30 and $60 \mathrm{~m}$, i.e. of the same distance as the stacked sediment packages. Even if they cannot be linked to individual highs and troughs because of the navigation uncertainties, the short distance amplitude variations show that the stacked sediment packages strike parallel to the slope. This is in agreement with the multibeam bathymetry data presented by Cattaneo et al. (2004). Computer-aided interpretation of the Chirp data facilitates the automatic picking of coherent seismic events, and depth conversion of the seismic records. Fig. 5 shows an example line and displays the geometry of the clinoform at the same length and height scales using water velocities of $1500 \mathrm{~m} / \mathrm{s}$ and assuming sediment velocities of $1550 \mathrm{~m} / \mathrm{s}$ based on core log information for the depth conversion of the line drawing. From this data representation it is obvious that the boundaries between the stacked sediments dip at shallow angles seaward. Generally, the inclination is between $3^{\circ}$ and $6^{\circ}$. The seabed 
is dipping very gently generally at less than one degree. Only the steepest of the seaward verges dip at up to $2^{\circ}$ (Correggiari et al., 2001). Cattaneo et al. (2004) already noted that there are generally no landward dipping top surfaces of the stacked sediments on the upper part of the slope. These authors also described in detail the dimensions and wavelength of the stacked sediment packages with respect to each other.

\subsection{Seabed amplitude variations}

The Chirp data seabed amplitude picks (Figs. 3 and $4 \mathrm{~b}$ ) show distinct variation both on a regional and local scale. On a regional scale (Fig. $3 \mathrm{~b}$ ) the amplitudes are of similar strength both in shallow waters $($ b30 m) and in deepwaters $(\mathrm{N} 80 \mathrm{~m})$. In the area with the undulated seabed topography, the amplitudes are generally significantly lower (red colours in Fig. 3b), but there are some high amplitude patches within the areas which are laterally extensive enough to correlate across adjacent seismic lines and which become graduallymore abundant seaward. In spite of the less dense data coverage in shallow water, the data suggest that the transition from high to low amplitudes is more abrupt when there is a regional change in slope of the seafloor, i.e. at the rollover point (in $30 \mathrm{~m}$ water depth) and at the bottomset. The 5-m accuracy of the ship's DGPS system facilitates a detailed analysis of the local seabed amplitude variations. On the scale of individual undulations, the seabed amplitudes vary systematically. The flat upslope limbs have high amplitudes that almost approach the amplitudes outside the foreset region, and the downslope limbs of the undulations have low amplitudes (Fig. 3a). The uppermost part of the slope, i.e. the foreset of the mud wedge clinoform (left end of Fig. 3a) dips as steeply as the downslope limbs of the undulations and still shows high seabed amplitudes. This indicates that the low amplitudes of the downslope flanks of the undulations are not caused by a change in seabed dip reflecting the wave energy away from the receiver. Amplitude decreases due to variations in seabed dip would not be expected to play a strong role anyway, as the seabed dips very gently even in the steepest parts of the undulations. Because of the low navigation accuracy of the Widescan sonar data, it is not possible to determine if the upslope (usually flat) and downslope flanks of the undulations correspond to high and low backscatter in the $100 \mathrm{kHz}$ Widescan data.

\section{Discussion}

The two main hypotheses for the development of the undulations offshore Ortona are (1) they developed as a result of some kind of differential sedimentation caused induced by currents either bottom currents or hyperpycnal flow. Given the shallow water setting, however, major differences to deep-water sediment waves (Flood, 1988; Flood et al., 1993) or the Humboldt Feature of California (Lee et al., 2002) would be expected. (2) The undulations may develop as a result of gravitationally induced slope movement, possibly in conjunction with earthquake induced ground motion. In the following we will discuss the arguments for and against these scenarios in the light of the new observations presented above.

\subsection{Deformation origin}

Movement of surface sediment along detachment planes, i.e. weak layers, has been documented for submarine slope failures elsewhere. The best documented example, albeit on a completely different scale is the Storegga Slide offshore mid-Norway. Detailed geotechnical investigations of this landslide revealed that it can only have happened with the presence of a weak layer and additional destabilization of the slope through seismic activity (Bryn et al., 2005; Solheim et al., 2005). Although the upper part of the Storegga Slide is about 100 times bigger than the seabed undulations in the Adriatic Sea, there are two important observations, which should be valid irrelevant of scale: (1) Slide planes, i.e. the basal detachment of the material, can dip at very low angles (b1 ${ }^{\circ}$ ), and (2) sediment block break-up - for example in the source region of the landslide which is affected by lateral spreading but also elsewhere - obeys the Mohr-Coulomb failure criterion, resulting in steep $\left(25^{\circ}\right.$ to $35^{\circ}$ ) headwalls and similar steeply dipping boundaries between individual blocks in the lateral spreading areas. The development of shear zones at these angles can successfully be modelled by Finite Element modelling (Kvalstad et al., 2005). Regardless of scale it should be expected that deformation and fragmentation of the sediments above a gently dipping slide plane should develop 
along similar steeply inclined shear zones, because they depend on the sediments ability to transport stress.

The undulations offshore Ortona in theAdriatic Sea are in some ways simlar to the situation in the Storegga area because both areas are characterized by fine grained, water rich sediments, and in both areas a potentially weak layer is present at the base of the stacked sediment packages (Correggiari et al., 2001; Cattaneo et al., 2004). The high seismicity in the Adriatic (Tinti and Armigliato, 2003) and the abundance of free gas in the subsurface (Fig. 5) could play a major role for reduction of effective stresses and destabilisation of sediments on this weak layer. However, the observed geometries in the lateral spreading blocks close to the Storegga Slide head wall and in other major slides differ in a significant way from the observations in our study area: the angle at which the block boundaries between individual blocks of lateral spreads dip is of the order of $35^{\circ}$ and offshore Ortona the angles of the undulation boundaries are dipping at $4^{\circ}$ to $5^{\circ}$ (Fig. 5). This is in stark contrast with Mohr- Coulomb failure of the sediments measured in triaxial stress tests which produced friction angles of $25^{\circ}$ to $35^{\circ}$ (Sultan et al., 2005). Even if it is invoked thatmovement is initiated at steeper angles and that sediment subsequently fails in a dynamic mode in which faulting could be controlled by the residual strength envelope (Goulty, 2002), it is difficult how such low angle deformation zones could develop between the undulations. We acknowledge, however, that the failure plane is oriented by an angle, the "internal friction angle", with respect to the principle stress direction, and the principle stress direction is not always vertical, especially during an earthquake or other external loading mechanisms.

To appreciate the validity of this argument against deformation, it is important to clearly distinguish between the weak layer and possible detachment plane at the base of the undulations and the boundaries of the undulations. Whereas many ways can be conceived how the strength of the weak layer can be decreased through earthquake loading and related fluid overpressures, so that it can fail at a low angle, these arguments do not hold in general for the boundaries of the undulations. In particular, the distribution of free gas observed as seismic blanking in the Chirp data does not align with individual undulations and it is difficult to envisage a sedimentary process that would lead to the deposition of sediments that are particularly prone to earthquake loading along the undulation boundaries. It is therefore difficult to see how the sediments could possibly transport stress at such low angles which is a prerequisite for the development of low-angle shear zones above a basal detachment surface. Finally, even for the weak layer, significant earthquake loading has to be invoked in order for it to act as a detachment surface, because at measured consolidation and overpressure even this layer is stable (Sultan et al., 2004).

\subsection{Depositional origin}

On a regional scale, the seabed reflection amplitudes are high in water depths of less than $30 \mathrm{~m}$ and more than 70-80 m which are the topset and bottomset of the shelf clinoform, respectively, but lower in the foreset area between 30 and $70 \mathrm{~m}$ (Fig. 4a). This can be explained by high sedimentation rates and hence higher water content and smaller acoustic impedance of the sediments in the foreset region in which the undulations are found. This difference in sedimentation rates, which is at the origin of the progradation of the Adriatic mud wedge with a clinoform geometry, could be the result of resuspension of fine-grained material in shallow waters during storm events in the topset and a gradual seaward decrease of sedimentation rates in the bottomset.

On the scale of individual undulations, the reflection amplitudes are higher for the upslope flat areas than for the downslope flanks (Fig. 3a). This is typical for sediment waves that propagate up-slope, because sediment waves have in general a higher accumulation of coarse grained, i.e. higher acoustic impedance, sediments on their up-current flanks (Masson et al., 2002). This agrees with the $210 \mathrm{~Pb}$ dating of Correggiari et al. (2001) who showed that accumulation rates are about four times higher for upslope parts of the seabed undulations than for the down-slope parts ranging from 4.1 to $16.1 \mathrm{~mm} / \mathrm{yr}$. However, if the differences in seismic amplitudes are due to grain size variations, these must be small as they were not resolved by the sedimentological studies carried out so far (Cattaneo et al., 2004).

The present current regime in the northern Adriatic is characterized by a cyclonic gyre driven by thermohaline currents and the prevailing winds (Artegiani et al., 1997). In the area offshore Ortona these currents are predominantly along-slope NW-SE. The bottom currents occasionally do have an 
offshore component which is not related to storm events (Puig et al., in press). Numerical modelling requires these downslope currents to transport sediments in order to explain the shape of the clinoforms (Niedoroda et al., 2005). Furthermore, there is some evidence that hyperpycnal flows may have taken place during major river floods in the geological past, i.e. before dams were build at the Apennine rivers (Syvitski and Kettner, in press).

If the seabed undulations form through sediment reworking as a result of bottom currents, the most likely oceanographic agent is the occasional occurrence of offshore directed bottom currents described by Puig et al. (in press). Because these events are directed downslope rather than slope parallel they are more likely to generate the slope parallel undulations observed in the sidescan sonar data (Fig. 3c) and the multi-beam bathymetry data. If the sediment undulations had originated by hyperpycnal flows before the dams were built, a line source had to be postulated for these flows as the undulations are laterally continuous. This seems unlikely, however, because the individual rivers would act as point sources. Hyperpycnal flows would also fail to explain the pronounced relatively abrupt change in dip direction of the seabed features (Fig. 1a). One would rather expect a gradual distal thinning of the undulating sediments and not the abrupt change at the bottomset (Cattaneo et al., 2004; Marsset et al., 2004).

The question remains what triggered the development of sediment waves in the study area. This question is not resolved for any occurrence of sediment waves, but Lee et al. (2002) have shown through numerical modelling that sediment waves can develop as a result of the interaction of bottom density currents with preexisting seafloor irregularities. As mentioned above, the area seaward of the seabed undulations is characterised by 20 to $30 \mathrm{~m}$ wide and 1 to $3 \mathrm{~m}$ high mud reliefs that rise from the maximum flooding surface (Cattaneo et al., 2003b, 2004; Trincardi et al., 2004). Their mounded shape, transparent interior, and varying onlap of the surrounding sediments suggests that they are the result of sediment mobilisation during early burial. It is conceivable that such sediment mobilisation features also existed during the early development of the undulations and are still imaged as the seismically chaotic zone at the base of the individual undulations (Fig. 5). In analogy to the present seabed topography in the distal part, such subsurface sediment mobilization would generate initial roughness, that could trigger the development of sediment waves (Lee et al., 2002). It is also possible that gravitational processes played a role in generating initial seafloor topography, but the seismic data are not conclusive in this respect.

\section{Conclusion}

The recently processed geophysical data support the findings of Cattaneo et al. (2004) that differential sedimentation plays a major role in the formation of seabed undulations in the Holocene sediments offshore Ortona, at least for the uppermost section of the mud wedge in water depth less than $70 \mathrm{~m}$. The regional variation in seabed amplitudes can be explained by different sedimentation rates and preferential deposition of fine grained material in the foreset. The difference of seabed reflection strength over individual undulations may be explained by preferential deposition on the upslope flanks of the undulations. Finally, the strike direction of the undulations agrees with bottom Ekman transport as a mechanism to maintain the undulated topography (Puig et al., in press).

The depth conversion of the seismic sections shows, on the other hand, that the boundaries between the seabed undulations dip at angles of $4-5^{\circ}$ against the horizontal. It is mechanically not possible that these boundaries represent fault planes, if the principle stress direction is vertical, as sidement in this area - although very soft - has an angle of friction of $25^{\circ}$ to $35^{\circ}$. This means that the boundaries of the undulations cannot be caused by sediment deformation governed by the Mohr Coulomb failure criteria under such conditions. This does not exclude, however, that the base of the undulations can behave as aweak layer and liquefy under earthquake load.

If Mohr Coulomb failure can be ruled out for the formation of the seabed undulations it may still be possible that their deformation is governed by a different law and frequently submarine creep has been invoked for this. However, even in the best-documented example for submarine creep (Hill et al., 1982) the fault dip in the extensional area agrees with Mohr-Coulomb failure. Therefore a fundamentally new creep process for submarine slope failure would have to be invoked to explain the structures of Ortona by slope failure. Such a process may involve plastic deformation of rocks and 
continuous failure that is governed by residual shear strength (Goulty, 2002). However, as such a process has not been shown theoretically or in field experiments to produce structures as found in the study area, we prefer to interpret the uppermost section of the margin-parallel undulations offshore Ortona as sediment waves. It is still possible that gravitational forces have played a role during the initial formation of seabed topography that might have triggered the formation of sediment waves subsequently. This is supported by the fact that the sediments farther downslope (N70 m) show mud reliefs that can be the result of sediment mobilization (Trincardi et al., 2004).

\section{Acknowledgements}

This manuscript benefited from constructive criticism by Homer Lee and an anonymous reviewer. Financial support was provided from projects EUROSTRATAFORM (EC contract n. EVK3-CT-200200079), EURODELTA (EC contract n. EVK3-CT- 2001-20001). We thank captain and crew of N/O Urania (CNR); this is ISMAR (CNR) contribution 1521. We thank SeismicMicrotechnology for providing an academic license for KingdomSuite, and Landmark Graphics for providing ProMAX under the Landmark Graphics University Grant Program. This is ISMAR contribution number 1521.

\section{References}

Artegiani, A., Bregant, D., Paschini, E., Pinardi, N., Raicich, F., Russo,A., 1997. The Adriatic Sea general circulation: Part II. Baroclinic circulation structure. J. Phys. Oceanogr. 27, 1515-1532.

Bryn, P., Berg, K., Forsberg, C.F., Solheim, A., Kvalstad, T.J., 2005.Explaining the Storegga Slide. Mar. Pet. Geol. 22 (1-2), 11-19.

Bull, J.M., Quinn, R., Dix, J.K., 1998. Reflection coefficient calculation from marine high resolution seismic reflection (CHIRP) data and application to an archaeological case study. Mar. Geophys. Res. 20, 1-11.

Carlson, P.R., 1978. Holocene slump on continental shelf off Malaspina Glacier, Gulf of Alaska. Am. Assoc. Pet. Geol. Bull. 62, 2412-2425.

Cattaneo, A., Correggiari, A., Langone, L., Trincardi, F., 2003a. The late-Holocene Gargano subaqueous delta, Adriatic shelf: sediment pathways and supply fluctuations. Mar. Geol. 193, 61-91.

Cattaneo, A., Correggiari, A., Penitenti, D., Trincardi, F., Marsset, B., 2003b.Morphobathymetry of small-scalemud reliefs on the Adriatic shelf. In: Locat, J., Mienert, J. (Eds.), Submarine Mass Movements and their Consequences. Kluwer, Amsterdam, pp. 401-408.

Cattaneo, A., Correggiari, A., Marsset, T., Thomas, Y., Marsset, B., Trincardi, F., 2004. Seafloor undulation pattern on the Adriatic shelf and comparison to deep-water sediment waves. Mar. Geol. 213 (1-4), 121-148.

Clay, C.S., Liang, W.L., 1962. Continuous seismic profiling with matched filter detector. Geophysics 27 (6), 786-795. Correggiari, A., Trincardi, F., Langone, L., Roveri, M., 2001. Styles of failure in Late Holocene highstand prodelta wedges on the Adriatic shelf. J. Sediment. Res. 71, 218-236.

Flood, R.D., 1988. A lee wave model for deep-sea mudwave activity. Deep-Sea Res. 35 (6), 973-983.

Flood, R.D., Shor, A.N., Manley, P.L., 1993. Morphology of abyssal mudwaves at Project MUDWAVES sites in the Argentine Basin. Deep-Sea Res. II 40 (4/5), 859-888.

García-García, A., Orange, D., Miserocchi, S., Correggiari, A., Langone, L., Lorenson, T., Trincardi, F., Nittrouer, C., in press What controls the distribution of shallow gas in the Western Adriatic Sea? Cont. Shelf Res. 
Gardner, J.V., Prior, D.B., Field, M.E., 1999. Humboldt Slide; a large shear-dominated retrogressive slope failure. Mar. Geol. 154 (1-4), 323-338.

Goulty, N.R., 2002. Mechanics of layer-bound faulting in fine-grained sediments. J. Geol. Soc. 159, 239-246.

Hill, P.R., Moran, K.M., Blasco, S.M., 1982. Creep deformation of slope sediments in the Canadian Beaufort Sea. Geo Mar. Lett. 2,163-170.

Hovland, M., Curzi, P.V., 1989. Gas seepage and assumed mud diapirism in the Italian central Adriatic Sea. Mar. Pet. Geol. 6, 161-169.

Kvalstad, T.J., Andresen, L., Forsberg, C.F., Berg, K., Bryn, P., Wangen, M., 2005. The Storegga slide: evaluation of triggering sources and slide mechanics. Mar. Pet. Geol. 22 (1-2), 245-256.

Le Bas, T.P., Masson, D.G., 1995. Improved geological interpretation by automatic registration of marine bathymetry and sonar imagery. Bull. Soc. Fr. Photogramm. Teledetec. 137, 56-61.

Lee, H.J., Baraza, J., 1999. Geotechnical characteristics and slope stability in the Gulf of Cadiz. Mar. Geol. 155, 173-190.

Lee, H.J., Syvitski, J.P.M., Parker, G., Orange, D., Locat, J., Hutton, E. W.H., Imran, J., 2002. Distinguishing sediment waves from slope failure deposits: field examples, including the 'Humboldt Slide',and modelling results. Mar. Geol. 192, 79-104.

Leet, L.D., 1982. Physical Geology. Prentice-Hall, Englewood Cliffs. Locat, J., Lee, H.J., 2000. Submarine Landslides: Advances and Challenges. 8th International Symposium on Landslides, Cardiff, U.K.

Marsset, T., Marsset, B., Thomas, Y., Cochonat, P., Cattaneo, A., Tricardi, F., 2004. Analysis of Holocene sedimentary features on the Adriatic shelf from 3D very high resolution seismic data (Triad survey). Mar. Geol. 213 (1-4), 73-89.

Masson, D.G., Jacobs, C., Le Bas, T.P., Hühnerbach, V., 2000. Surficial Geology, Atlantic Frontier Environment Surveys. Southampton Oceanography Centre, p. 41.

Masson, D.G., Watts, A.B., Gee, M.J.R., Urgeles, R., Mitchell, N.C., Le Bas, T.P., Cannals, M., 2002. Slope failures on the flanks of the western Canary Islands. Earth Sci. Rev. 57, 1-35.

Mulder, T., Cochonat, P., 1996. Classification of offshore mass movements. J. Sediment. Res. 66 (1), 43-57. Niedoroda, A.W., Reed, C.W., Das, H., Fagherazzi, S., Donoghue, J.F.,

Cattaneo, A., 2005. Analyses of a large-scale depositional clinoformal wedge along the Italian Adriatic coast. Mar. Geol. 222-223, 179-192.

Puig, P., Ogston, A.S., Guillén, J., Fain, A., Palanques, A., in press. Sediment transport processes from the topset to the foreset of a crenulated clinoform (Adriatic Sea). Cont. Shelf Res.

Quinn, R., Bull, J.M., Dix, J.K., 1998. Optimal processing of marine

high-resolution seismic reflection (CHIRP) data. Mar. Geophys. Res. 20, 13-20.

Schock, S.G., LeBlanc, L.R., Mayer, L.A., 1989. Chirp subbottom profiler for quantitative sediment analysis. Geophysics 54 (4), 445-450.

Solheim, A., Berg, K., Forsberg, C.F., Bryn, P., 2005. The Storegga Slide complex: repetitive large scale sliding with similar cause and development. Mar. Pet. Geol. 22 (1-2), 97-107.

Sultan, N., Cochonat, P., Canals, M., Cattaneo, A., Dennielou, B., Haflidason, H., Laberg, J.S., Long, D., Mienert, J., Trincardi, F.,Urgeles, R.,Vorren, T.O.,Wilson, C., 2004. Triggering mechanisms of 
slope instability processes and sediment failures on continental margins: a geotechnical approach. Mar. Geol. 213 (1-4), 291-321.

Sultan, N., Berné, S., Canals, M., Cattaneo, A., Frigola, J., Lafuerza, S., Trincardi, F., Urgeles, R., 2005. Experimental study on deformation and strenght behaviour of marine sediments from the Adriatic shelf: first results from the Promess1 drilling project. EGU Geophysical Research Abstracts, 7, 05192.

Syvitski, J.P.M., Kettner, A.J., in press. On the flux of water and sediment into the Northern Adriatic. Cont. Shelf Res.

Tinti, S., Armigliato, A., 2003. The use of scenarios to evaluate the tsunami impact in southern Italy. Mar. Geol. 199, 221-243. Trincardi, F., Cattaneo, A., Correggiari, A., Ridente, D., 2004.

Evidence of soft sediment deformation, fluid escape, sediment failure and regional weak layers within the late Quaternary mud deposits of the Adriatic Sea. Mar. Geol. 213 (1-4), 91-119. 


\section{Figures}
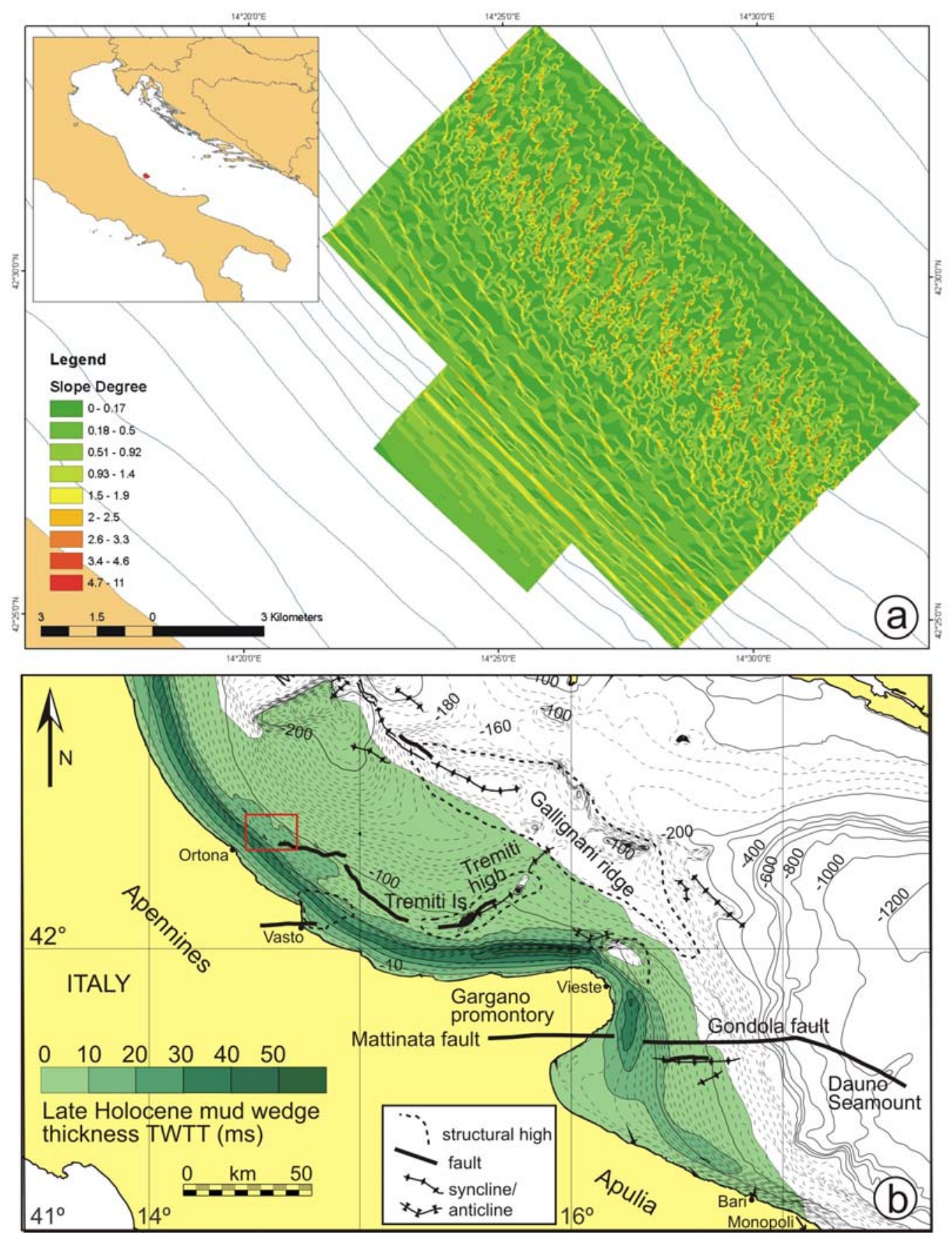

Figure 1: The study area (red box in b) is located in the western central Adriatic Sea (regional map) and comprises the late Holocene high-stand systems tract whose thickness is reported in green shades from Correggiari et al., 2001 in b. a) is the multibeam bathymetry derived slope gradient map showing the pronounced difference between the NW-SE striking undulations in the foreset and the SW-NE striking mud relief structures in the distal part. 

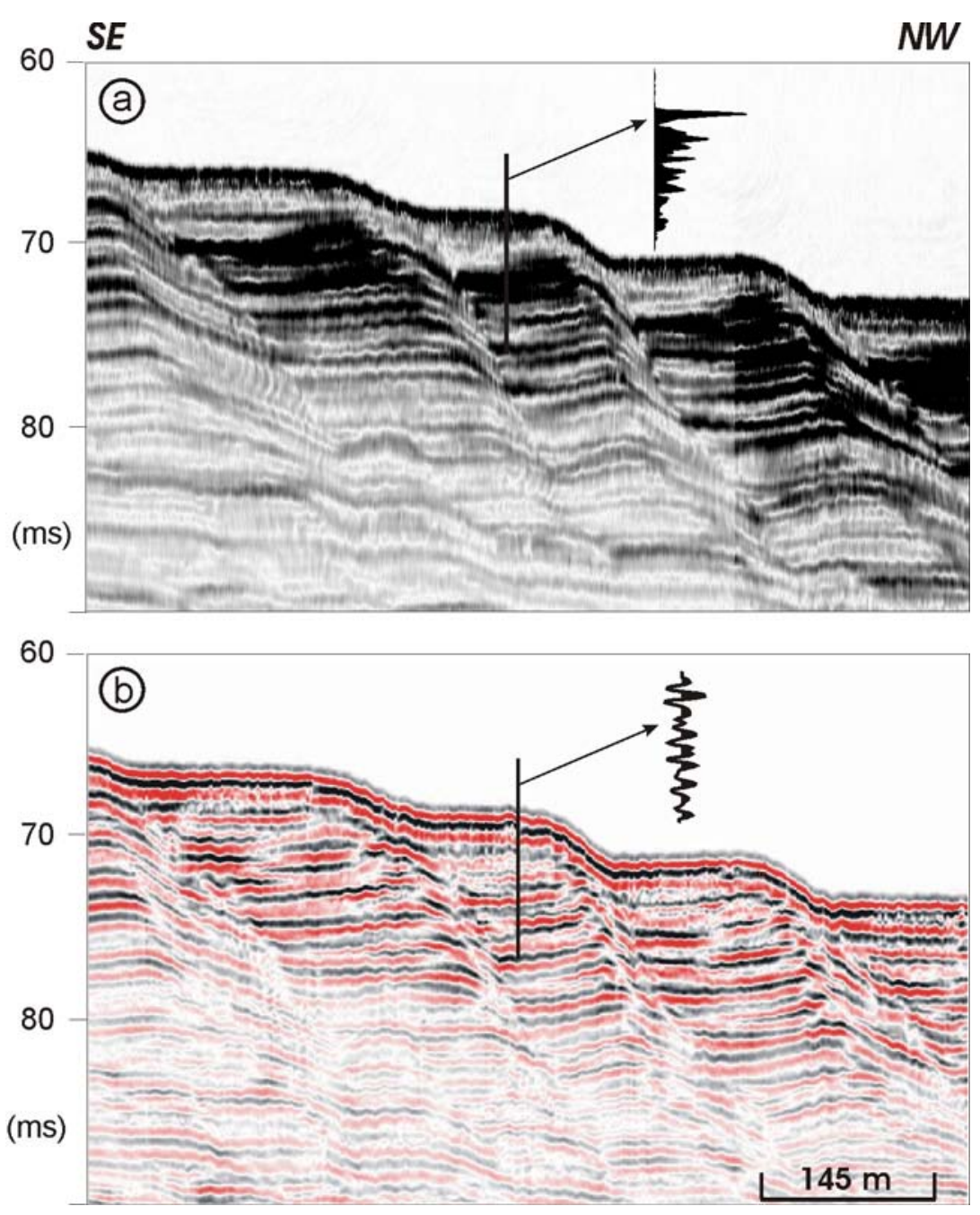

Figure 2: Comparison of the normal Chirp data (convoluted and amplitude-squared) with the reprocessed low-frequency zero-phase filtered data. This processing is required to apply automated picking routines to the data. 

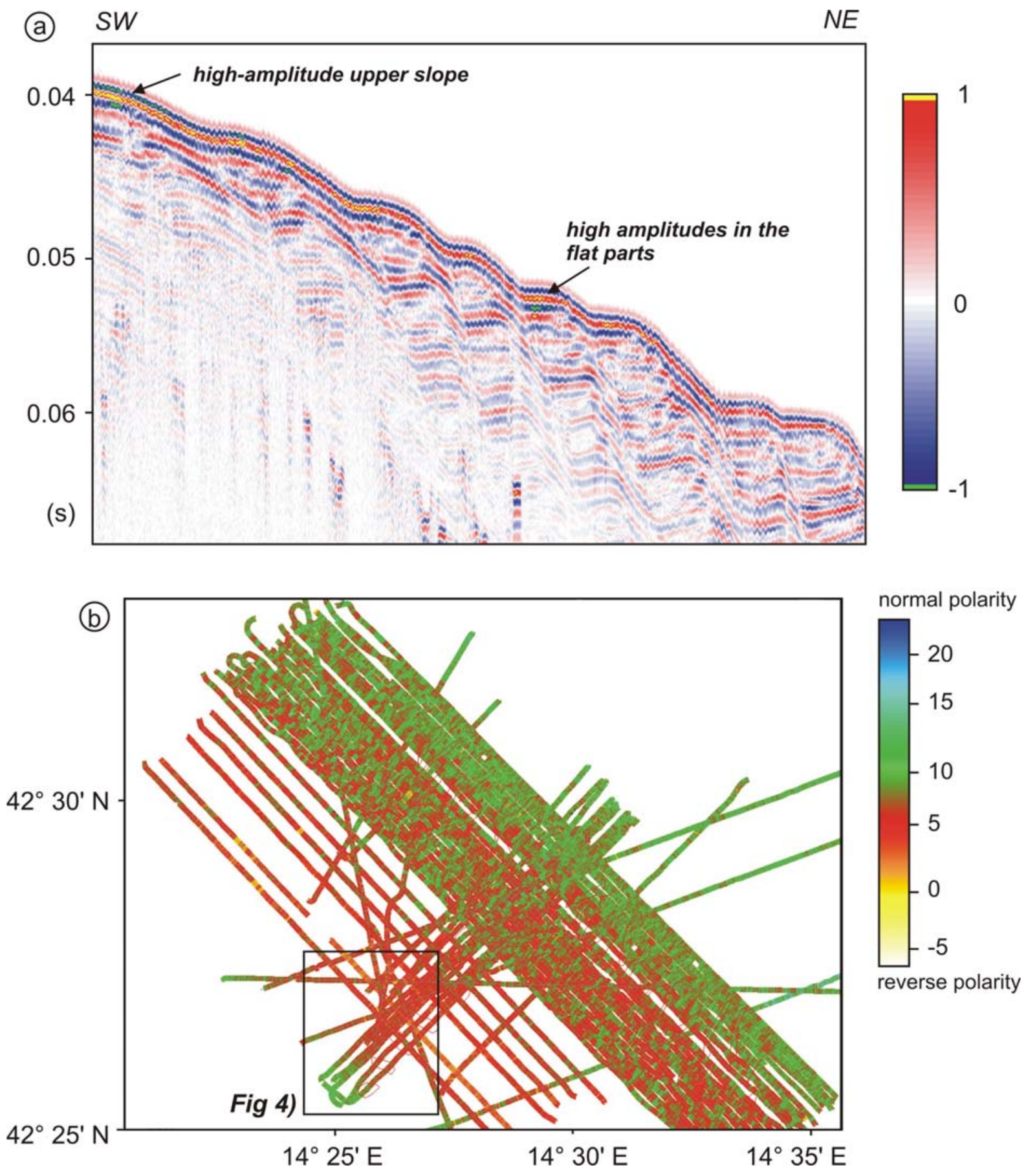

Figure 3: Seabed amplitudes extracted from the processed high-resolution Chirp data. a) Example of a seismic line (position in the zoom in Figure 4a). b) Seabed amplitude map extracted from the processed Chirp data. Seabed corresponds to the first peak (red) in a). 
(a)

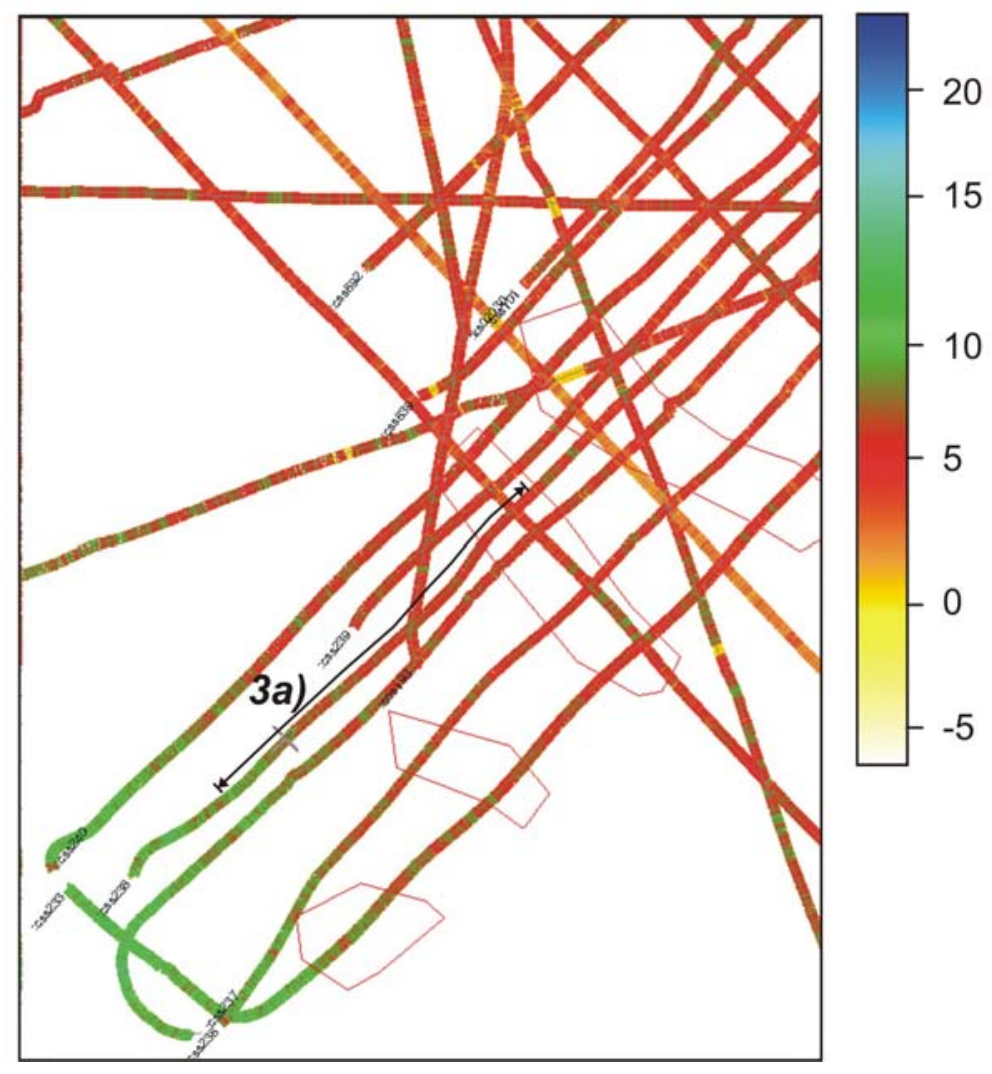

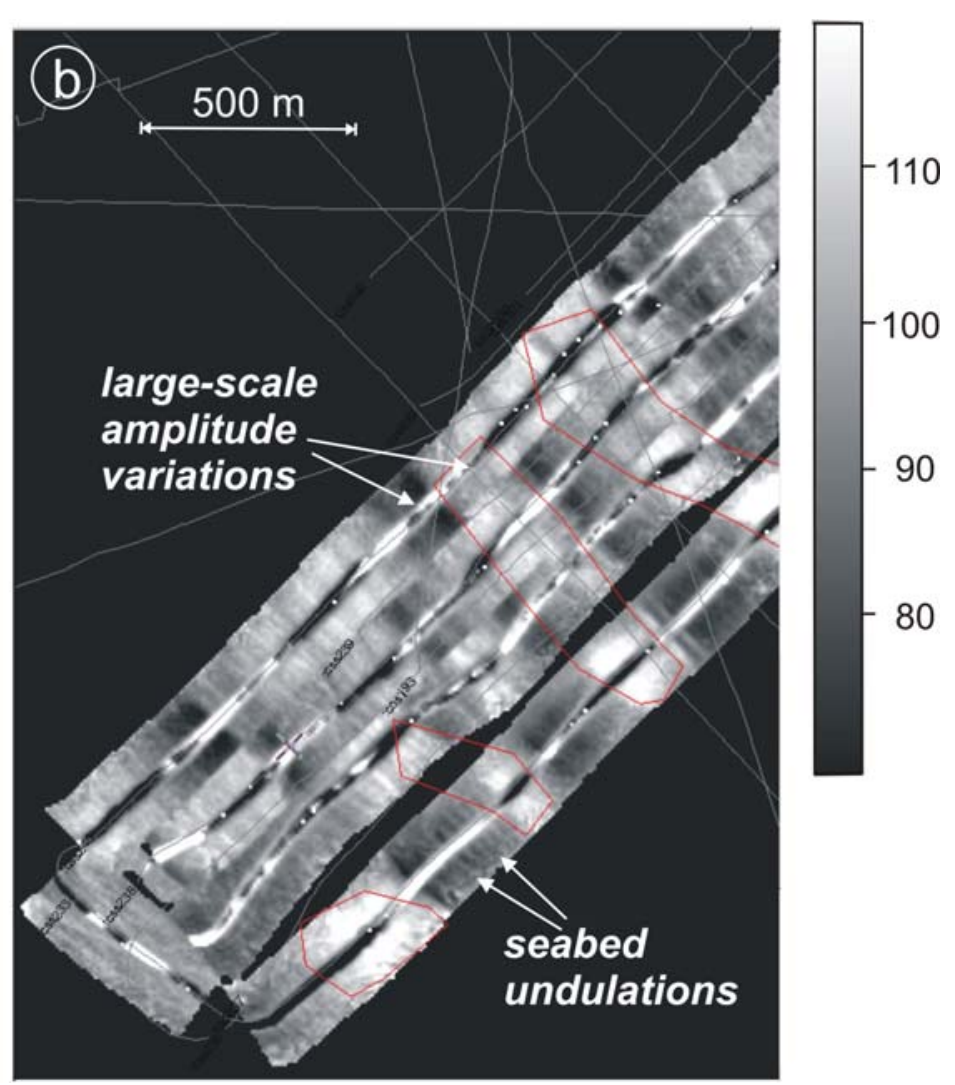

Figure 4: a) Zoom of seabed amplitudes for upper slope (box in Figure 3b). b) Backscatter data from the Widescan system for the same area. Light colours in the sidescan sonar data indicate high backscatter, and dark colours low backscatter. The red polygons highlight the high backscatter areas for comparison between the figures. 


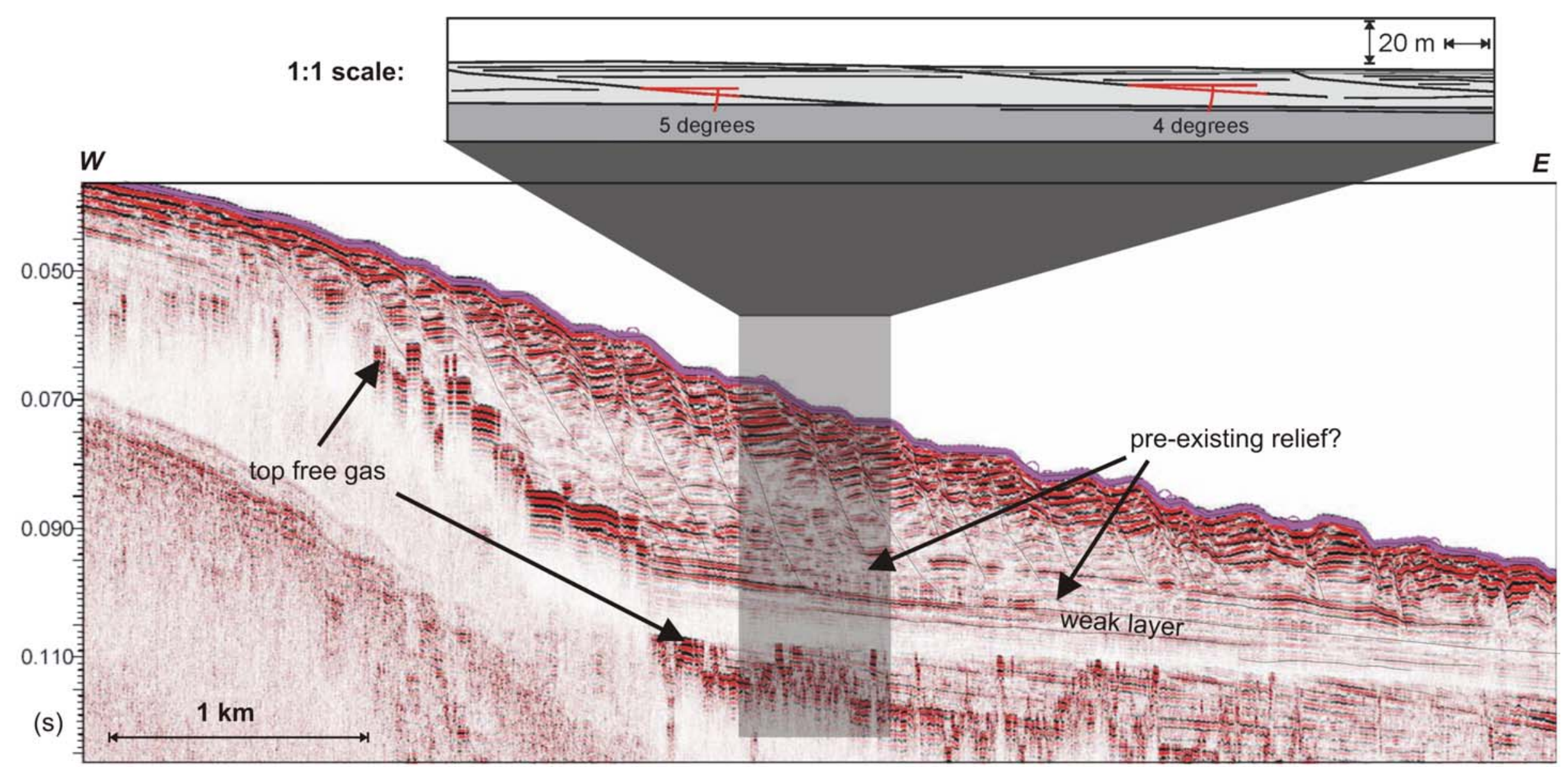

Figure 5: Depth-converted section of Chirp line CSS238 showing the true dip of the interfaces between the stacked sediment packages. The seismically opaque area labelled "weak layer" has been subjected to triaxial stress tests within the PROMESS project. Initial results show that layer is weaker than the remaining strata. Furthermore, free gas is found at shallow depth within the study area indicating overpressures and reduced effective stresses. 